\title{
SYPHILIS OF THE LUNG
}

By R. S. BRUCE PEARSON, D.M., Medical Registrar, Guy's Hospital, and S. DE NAVASQUEZ, M.D., Assistant Lecturer in Pathology, Guy's Hospital Medical School.

From the Department of Pathology, Guy's Hospital Medical School.

THE following two cases of syphilis of the lung are recorded mainly in order to draw attention to a condition which, though not rare, is sufficiently uncommon to be readily overlooked. The pathological findings in one case are described in detail and suggestions are made regarding the evolution of the clinical and radiological changes in the lung which sometimes accompany acquired syphilis. An attempt is also made to relate the pathological state of the lung to the radiological appearances.

Case I.-J. C., 59 years, was admitted for pain in the chest and breathlessness. Apart from measles as a child, he had been in good health till eight years before, when he began to have attacks of dyspnœa. These came on only when he was at work, which consisted in sweeping up dust containing flour. The attacks were regarded as asthmatic in origin, precipitated by contact with flour to which he had become sensitive.

About a month before admission he experienced a sharp attack of pain behind the upper end of his sternum, extending down the inner side of both arms : on standing still the pain went. It had recurred on a number of occasions since, always during exercise. Once or twice, shortly before admission, he had coughed up bloodstained sputum, and for two weeks he had had to sleep propped up with pillows, because he became breathless on lying down. He had also noticed some swelling of the feet during the week before admission.

On admission he was dyspnoic, breathing shallowly and at the rate of thirty a minute. He complained of a dull pain in the precordial area. His pulse was regular between 90 and roo, and collapsing in character. He was cyanosed.

Republished at the request of the Editors of The British Journal of Venereal Diseases. With acknowledgements to, and permission of, the Editor of the Guy's Hospital Reports. 


\section{BRITISH JOURNAL OF VENEREAL DISEASES}

There was some distension of the veins in the neck, and carotid pulsation was observed to be more marked on the right than the left side. The apex beat was just outside the mid-clavicular line, suggesting moderate

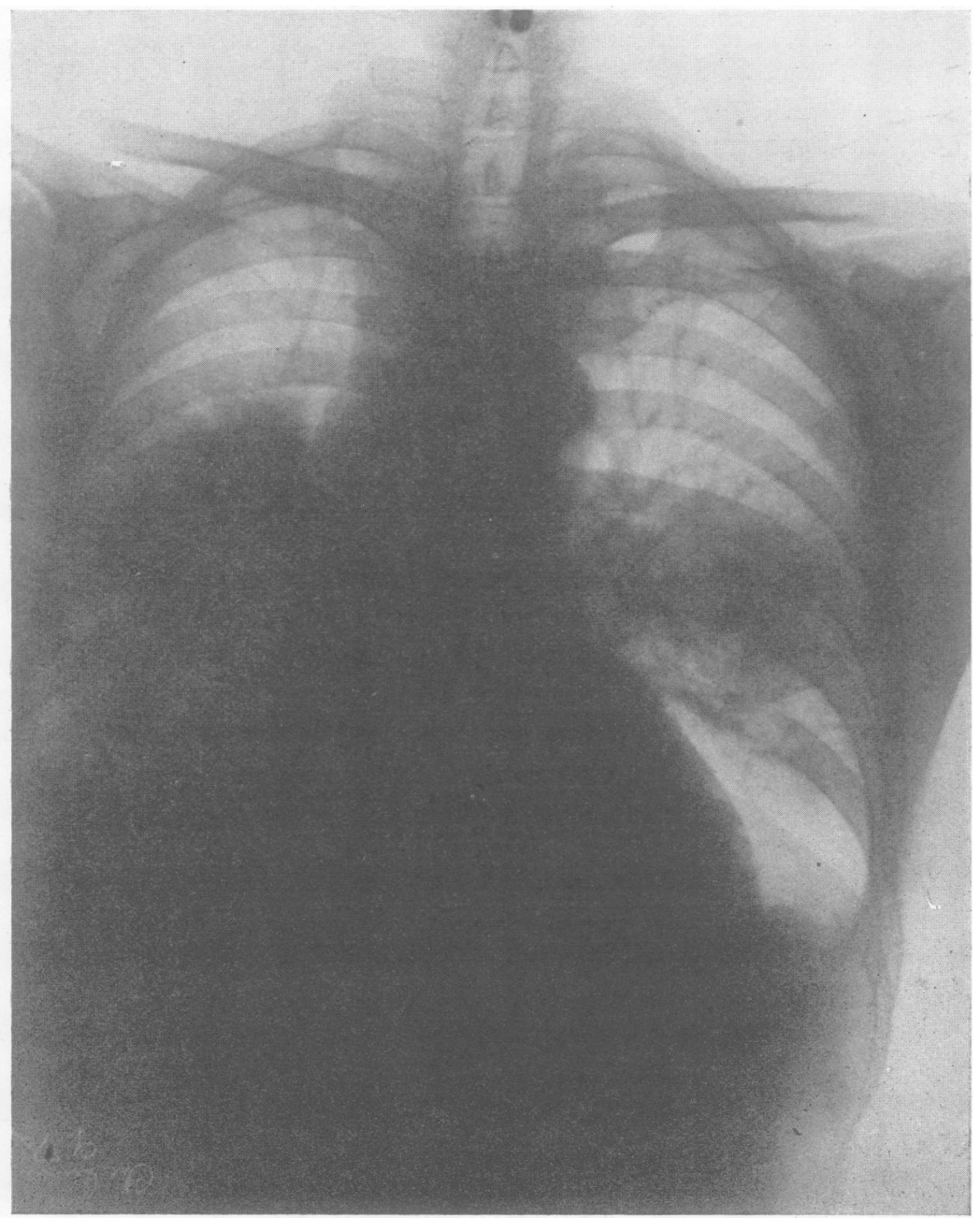

FIG. I.-Showing extensive area of infiltration in right lung.

enlargement of the heart. The blood pressure was II2/56. There was some œedema of the feet.

On auscultation loud systolic and diastolic murmurs were heard in the aortic area. At the apex there was a soft diastolic murmur conducted from the aortic area. There were generalised rhonchi over the chest, and an 


\section{SYPHILIS OF THE LUNG}

area of bronchial breathing extending outwards from the sternum at the level of the second interspace towards the right axilla. Above this was an area of diminished air entry and râles. There was a corresponding area

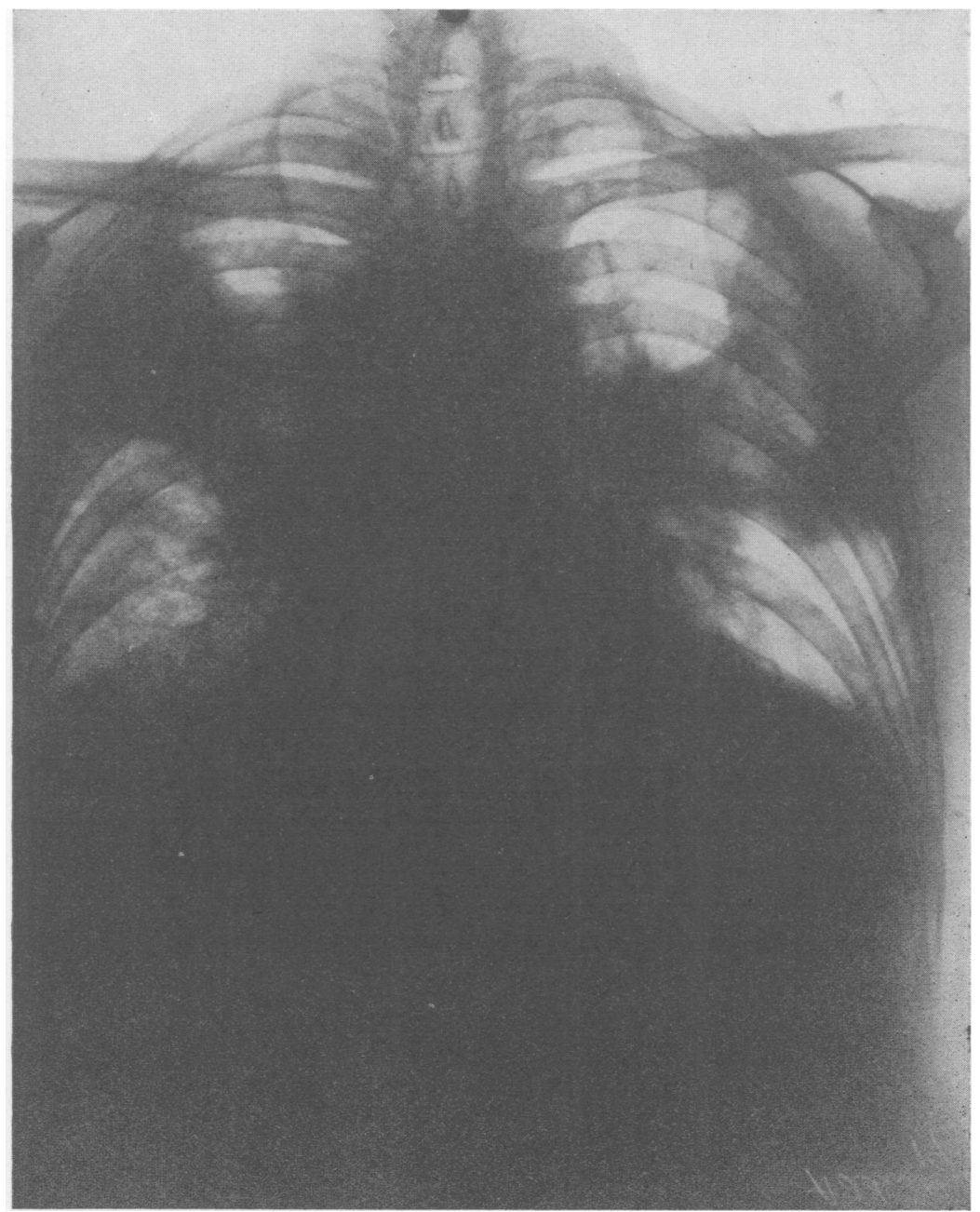

FIG. 2.-Showing wedge-shaped areas of infiltration in middle third of both lungs. Trachea displaced to right. Aneurismal dilatation of aorta is well shown.

behind. The pupils were equal, and reacted to light and accommodation. The limb reflexes were all present and equal. The abdomen showed no abnormality. The urine contained no blood or sugar, but traces of albumen were found. The Wassermann and Kahn reactions were 


\section{BRITISH JOURNAL OF VENEREAL DISEASES}

both strongly positive. The blood picture showed a red cell count of 4.2 million, and white cells 10,200 per c.mm. ; of these 69 per cent. were polymorphs, 25 per cent. lymphocytes, 2 per cent. large mononuclears, and 2 per cent. eosinophils.

The patient was severely ill on admission, and although he had evidence of heart failure it was observed throughout that he appeared much more cyanosed and much more distressed than one would have expected from the size of his heart, the moderate aortic lesion, the slight œdema of the feet, and the fact that all evidence of congestion of the veins disappeared soon after admission.

A radiograph (Fig. I), taken at Out Patients ten days before admission, showed an area of infiltration on the right side of the chest in the lower and middle zones with slight deviation of the mediastinum to the right. The mediastinum was thickened and partly obscured in its posterior part. On admission, opacity of the lower part of the right upper lobe and the presence of a large shadow at the left root were reported (Fig. 2). Radiographs taken ten days after admission showed no change in this appearance. No further radiographs were taken.

In the first week after admission the patient continued to be very ill, and speaking was sufficient to make him short of breath. He was partly relieved by administration of oxygen through a nasal catheter. The mouth temperature was persistently low and varied between $95^{\circ}$ and $97^{\circ}$, while his pulse, which was good in quality, varied between 80 and Ioo. His sputum, which was very scanty, contained no tubercle bacilli on the two occasions it was examined. During the second week after admission respiration became easier and cyanosis less marked, and he continued in this improved state for three weeks, when he suddenly became much worse, the respiration rate rising to 40 per minute, though pulse and temperature remained unaltered. He was then ashen coloured and cyanosed, with grunting respiration. He became progressively worse and died two days later (a little over a month after admission) with a terminal temperature of 102 and pulse of 140.

\section{Autopsy}

Autopsy was performed twenty-two hours after death, the body having been kept in a refrigerated mortuary. 


\section{SYPHILIS OF THE LUNG}

The body was that of an elderly male of slight build with moderate œdema of the ankles and severe hæmolytic staining of the skin and subcutaneous tissues of the trunk and limbs along the course of the superficial vessels.

Cardiovascular System.-The pericardial sac contained a slight excess of clear yellow fluid. The visceral layer of the pericardium showed two large irregular milk patches on the anterior surface of the right ventricle and on the posterior surface of the right auricle. The heart weighed $375 \mathrm{gm}$. All the chambers were dilated and contained post-mortem clot. The heart was enlarged to the right and to the left but was not hypertrophied. The myocardium was stretched and thinned and showed severe hæmolytic staining of its outer twothirds and some adiposity of the right ventricular apex ; it was soft and flabby and showed considerable loss of muscular texture.

The endocardium was stained a dark red from hæmolysis. The mitral valve showed some puckering and pocketing along the entire closure line of the aortic cusp and to a point midway along the closure line of the posterior cusp ; there were no vegetations. The aortic ring measured $5.8 \mathrm{~cm}$. in circumference and was slightly thickened but not dilated. The aortic cusps showed a moderate contraction of the free margins with irregular thickening and rolling of the edges. This was most marked in the anterior cusps. The mouths of the coronary arteries were displaced in position by scars in the surrounding aortic wall, but were not narrowed since a $4 \mathrm{~mm}$. probe passed quite freely. The remaining valves were normal. The first $5 \mathrm{~cm}$. of the aorta above the aortic rings showed a few streaks of superficial atheroma. Beyond this point, there was transverse and longitudinal scarring of the intima indicating syphilitic aortitis and the aorta gradually dilated to form a fusiform aneurysm whose maximum circumference $8 \mathrm{~cm}$. above the aortic ring was greater than $9 \mathrm{~cm}$. The second part of the ascending thoracic aorta showed severe calcified atheroma with thinning and scarring of the overlying intima. The arch of the aorta showed slight superficial atheroma which was also present at the lower end of the abdominal portion. Pulmonary artery and venæ cavæ were normal except for hæmolytic staining of the intima.

Respiratory System.-The right and left pleural cavities v.D. 


\section{BRITISH JOURNAL OF VENEREAL DISEASES}

contained $2 \frac{1}{2}$ and 3 pints of clear light yellow fluid respectively. The pleuræ showed severe bilateral apical scarring, which was worse at the right apex, and fibrous adhesions at both bases and mediastinum. The right and left lungs weighed 600 and $625 \mathrm{gm}$. respectively. Both lungs were compressed and smaller than normal. The apical parts of both upper lobes were dry, air containing and uniformly resilient. The right upper and middle lobes were adherent to one another at the interlobar septum, which was in turn connected to the parietal pleura and mediastinum by fibrous adhesions. The middle third of the right lung, comprising the lower part of the upper lobe and the upper parts of the middle and lower lobes, was consolidated, firm and raised above the general surface of the lung. This area of consolidation formed a wedge with its apex at the hilum and its base at the pleura laterally. The base of the wedge contained two greyish white oval nodules, firm in consistency and which measured $3 \times 2.5 \mathrm{~cm}$. These nodules were subpleural in position and were covered by a larger circular scar measuring $6 \mathrm{~cm}$. in diameter. The apex of the wedge at the hilum contained three similar but smaller rounded nodules, the largest of which was $2 \mathrm{~cm}$. in diameter, clustered around the main bronchi. A similar wedgeshaped area, sharply demarcated from the air-containing lung above and below, occupied the middle third of the left lung and involved the lower half of the upper lobe and the upper half of the lower lobe, but no nodules were found in this area of consolidation. Both bases were air containing and free from consolidation.

The larynx was calcified. The trachea, main bronchi and bronchioles showed heavy hæmolytic staining of the mucous membrane which was otherwise normal in every respect throughout. The lumen of the bronchial tree was not disturbed in any way, although the bronchi appeared to be bunched together at the hilum. The right group of tracheo-bronchial lymph glands was slightly enlarged and soft, but apart from heavy carbon pigmentation appeared normal.

The alimentary system was normal except for moderate congestion of the mucosa of the gastro-intestinal tract. The liver showed moderate passive congestion only.

The lymphatic, urinary, endocrine and genital systems appeared normal. 


\section{SYPHILIS OF THE LUNG}

Microscopical Findings.-Sections were stained with hæmatoxylin and eosin, Van Gieson's and Weigert's stains for fibrous and elastic tissues, Levaditi's method for spirochætes and von Kossa's silver nitrate stain for calcium.

Sections from the periphery of the right middle lobe which was consolidated and contained the discrete nodules revealed areas of necrosis surrounded by granulation tissue (Fig. 3). These necrotic areas had irregular outlines and were sharply demarcated from the sur-

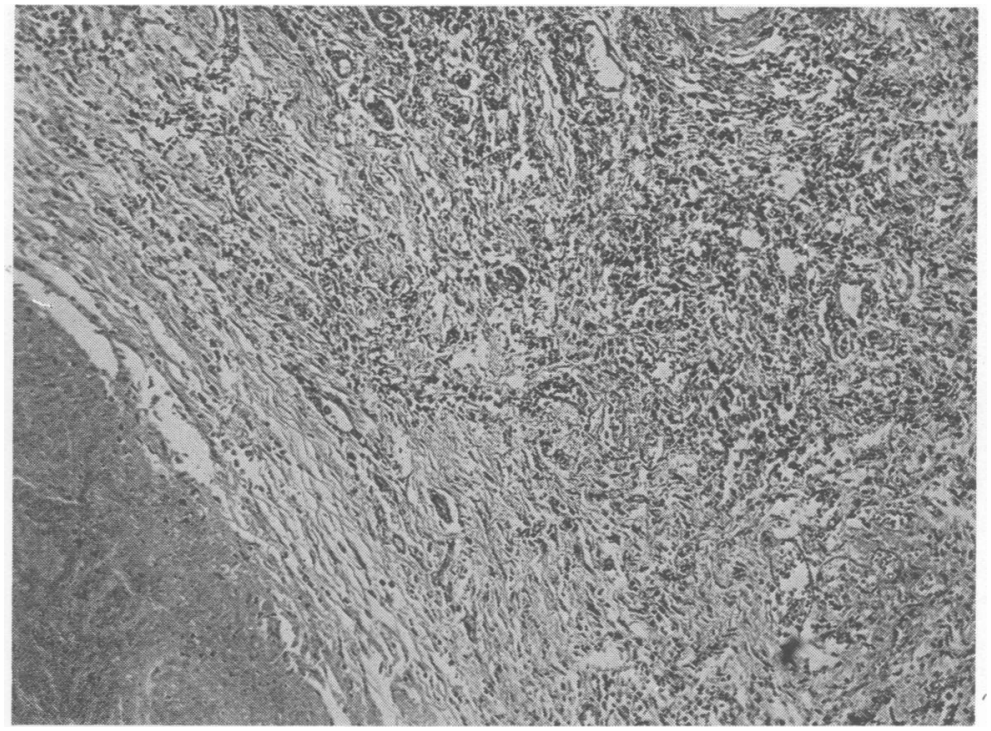

Fig. 3.-Case I. Microphotograph of an early gumma in the periphery of the right lung. H. and E. $\times 85$.

rounding granulation tissue. They consisted of an opaque eosinophilic material in which faint outlines of cellular structure could be made out. Nuclear and cytoplasmic débris was irregularly scattered throughout these areas. The most conspicuous feature, however, was the persistence of the alveolar pattern and the outlines of the blood vessels. This was even better demonstrated in sections stained with Weigert's elastin stain which displayed the elastic fibrils of the alveolar septa and of the blood vessels in a prominent manner (Fig. 4). In fact, the elastic tissue in the walls of the arteries and arterioles appeared to be increased while the walls themselves were thicker than normal. Extravasated red cells were 


\section{BRITISH JOURNAL OF VENEREAL DISEASES}

present in the periphery of the necrotic areas. The latter were surrounded by broad zones of granulation tissue consisting of fibrin, plasma cells, lymphocytes and fibroblasts which filled the alveoli in the vicinity. This granulation tissue showed abundant capillaries and was intersected by strands of collagenous fibrous tissue in which the arteries and arterioles showed severe endarteritis with narrowing of the lumen and thickening of the wall. In some areas these vessels showed infiltration of the adventitia and media with lymphocytes, plasma

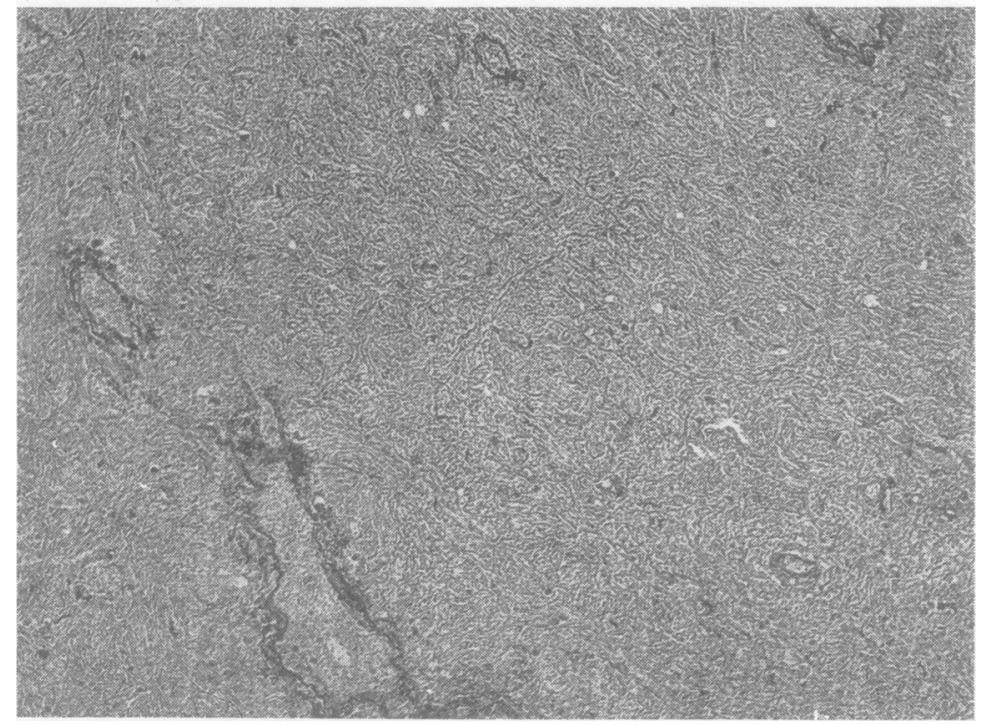

FIG. 4.-Case I. Microphotograph of a gumma in the right lung, showing the survival of the elastic tissue of the alveoli and blood vessels. Weigert and Van Gieson's stains $\times 50$.

cells, and an occasional polymorphonuclear leucocyte. The surrounding lung was consolidated, partly by compression and partly by a cellular exudate consisting of plasma cells and many macrophages containing altered blood pigment. These histological appearances were characteristic of a recent and active gummatous necrosis.

Sections from the hilum of the right middle lobe showed a gumma, similar in appearance to that described above, and in addition two areas of gummatous necrosis of greater size. These gummata consisted of a homogeneous eosinophilic tissue devoid of nuclear material but which showed the structural outlines of the lung and 


\section{SYPHILIS OF THE LUNG}

blood vessels and were surrounded by collagenous fibrous tissue (Fig. 5). The medium-sized bronchi in the immediate vicinity showed partial desquamation of the mucous membrane which was replaced by granulation tissue. There was severe peri-bronchial fibrosis which merged into the granulation tissue surrounding the areas of necrosis.

The consolidated lung substance lying between these two groups of gummata showed a diffuse interstitial and peri-bronchial fibrosis with endarteritis of the arterioles

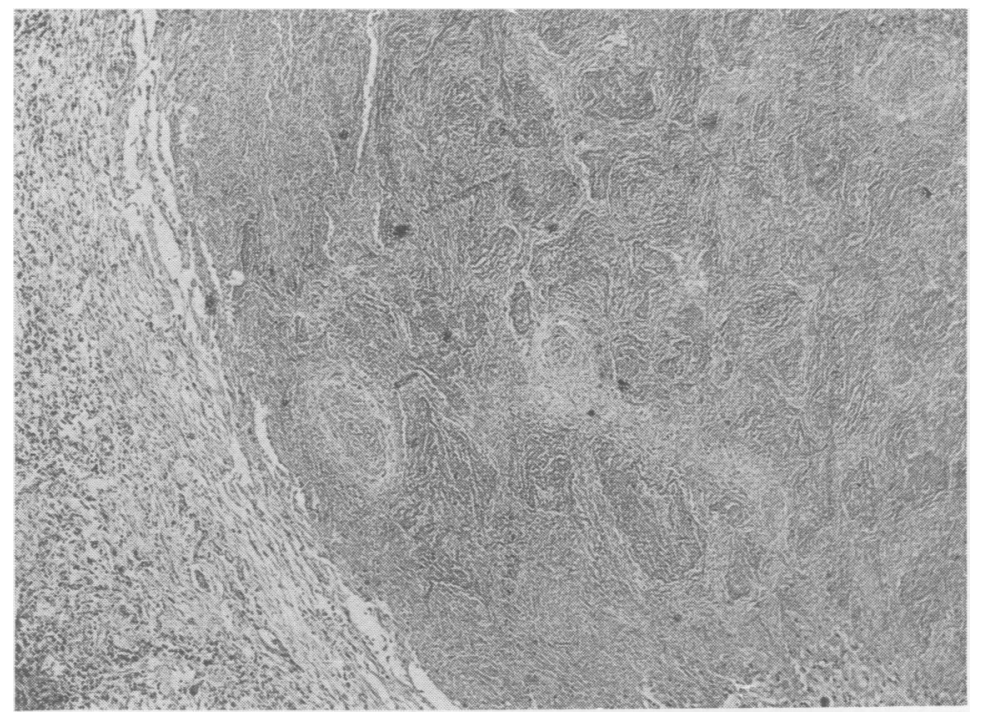

FIG. 5.-Case I. Microphotograph of a gumma from the hilum of the right lung, showing the surrounding fibrosis and the persistence of the vascular outlines in the centre. $H$. and $E$. $\times 50$.

and scattered inflammatory foci containing many lymphocytes and plasma cells. The alveoli were filled with œdema fluid and heavily pigmented macrophages, while the bronchi and bronchioles, although patent and devoid of contents, showed partial disappearance of the mucous membrane. Apart from the inflammatory foci, the histological appearance was similar to that of severe chronic passive congestion. The absence of calcification or carbon pigmentation was a distinct feature in the areas of necrosis and fibrosis and in sharp contrast when compared with tuberculomata or tuberculous fibrosis of the lung. There can be little doubt that the lesions in the right lung were of syphilitic origin. The presence of 


\section{BRITISH JOURNAL OF VENEREAL DISEASES}

gummata in both the periphery and hilum of the middle lobe and the focal collections of syphilitic granulation tissue would indicate that the interstitial and peribronchial fibrosis was of similar origin and represented the residual organisation of a diffuse syphilitic process.

The right upper lobe showed severe fibrosis of the apical pleura and underlying lung, which was distorted and heavily pigmented with carbon. The right lower lobe showed severe chronic passive congestion with thickening of the alveolar walls and moderate emphysema.

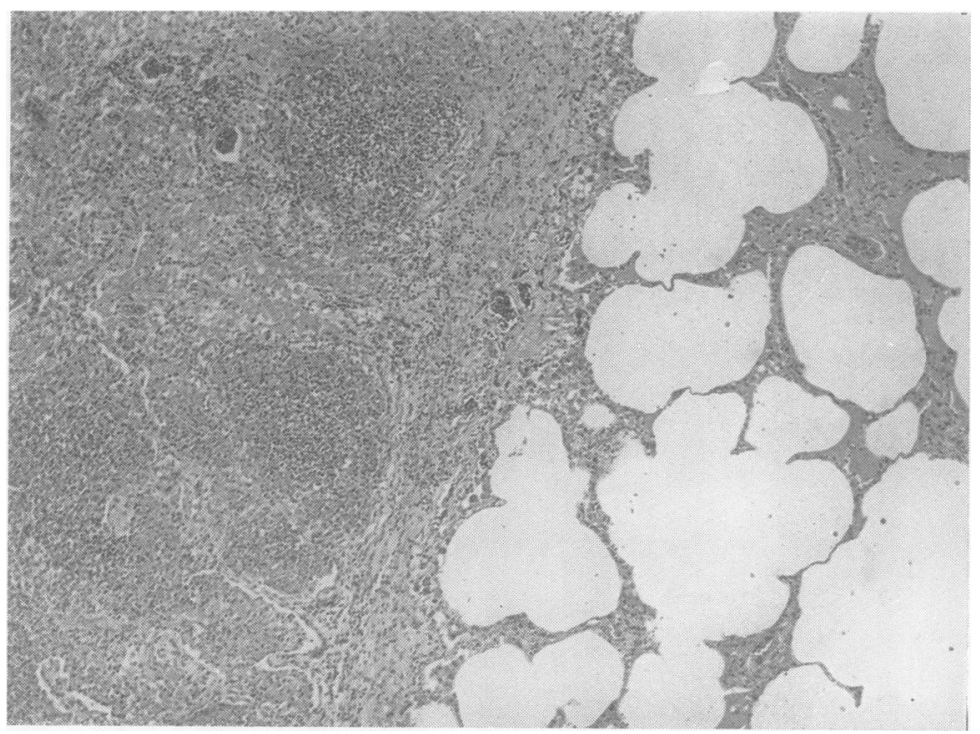

Fig. 6.-Case I. Microphotograph of the pneumonic area in the left lung, showing the sharply defined area of consolidation. H. and $\mathrm{E} . \quad \times 50$.

The left lung, which on naked-eye examination showed a similar wedge-shaped area occupying its middle third, revealed a somewhat different histological picture from that of the right lung. The appearance was more uniform throughout the consolidated area, which was rendered completely airless by a fibrino-cellular exudate filling the alveoli (Fig. 6). The bronchioles and alveolar walls were thickened by swelling of the lining epithelium and moderate dilatation of the capillaries together with many accompanying histiocytes and plasma cells. The alveolar exudate consisted of fibrin, numerous large clear cells, with pale rounded nuclei of the histiocytic type and plasma cells, while in many areas, cellular débris in 


\section{SYPHILIS OF THE LUNG}

the form of eosinophilic and basophilic granules was present as well. In addition, there were numerous small scattered foci involving groups of a dozen or so more or less completely necrosed alveoli (Fig. 7), though in sections stained with Weigert's stain, strands of alveolar elastic fibrils could be seen. Many of these foci were miliary in size and showed a preponderance of granular basophilic material, indicating dissolution of the nuclear elements, and a further stage in the necrotic process, while in others only the faint outlines of cells in a compact

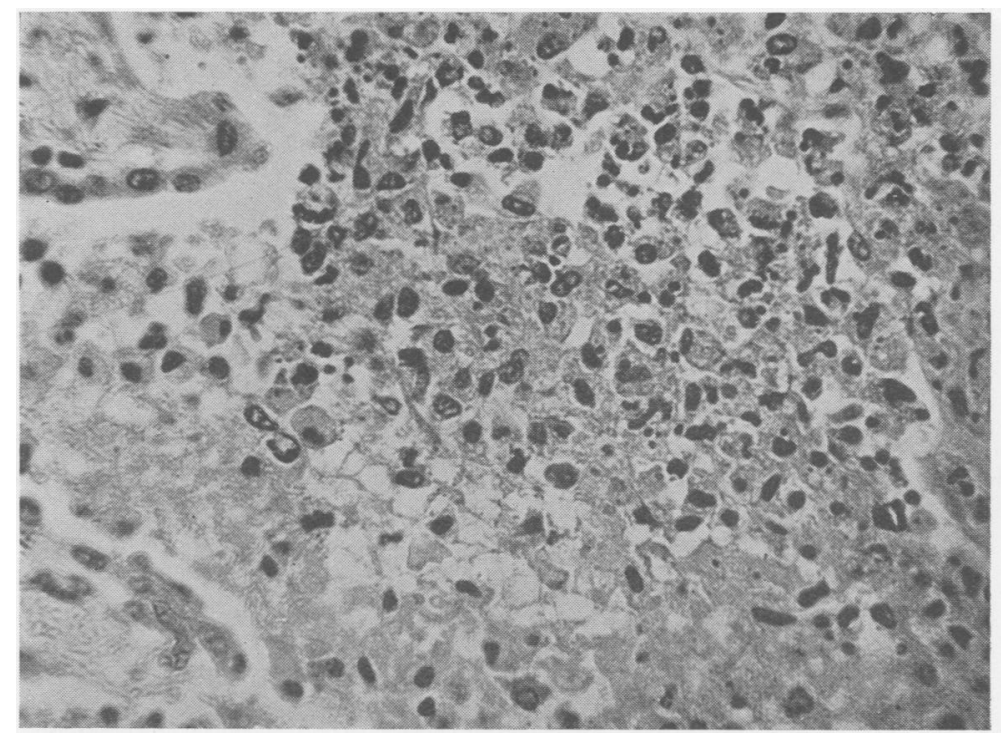

FIG. 7.-Case r. Microphotograph of the pneumonic area in the left lung, showing an area of necrosis and the character of the exudate. H. and E. $\times 360$.

mass could be seen. Polymorphonuclear leucocytes, endothelioid or giant cells of the Langhans type were absent.

These parenchymatous changes were accompanied by well-defined lesions of the arteries and arterioles. The latter showed an active arteritis with infiltration of the adventitia and media with many plasma cells, lymphocytes and macrophages, associated with partial fragmentation of the elastica. These changes, although conspicuous in the arteries, were also present in the small veins, while many of the vessels showed thrombosis and commencing organisation. 


\section{BRITISH JOURNAL OF VENEREAL DISEASES}

The bronchi were filled with the same fibrino-cellular exudate and necrotic material, which extended into the surrounding alveoli. Partial or complete rings of columnar epithelium could be seen in the midst of a necrotic area, which indicated surviving bronchial mucosa (Fig. 8).

Sections stained with Levaditi's method failed to reveal treponemata.

The lung above and below the consolidated area showed chronic passive congestion and emphysema only.

Consideration of the clinical and pathological data in

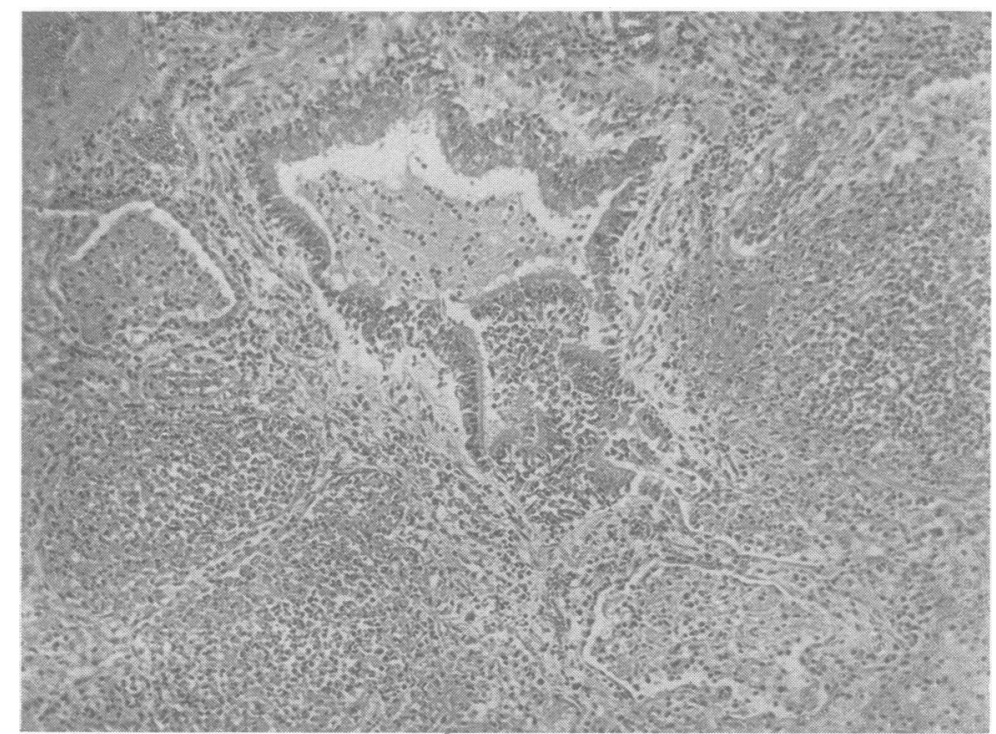

FIG. 8.-Case I. Microphotograph of the pneumonic area in the left lung, showing peri-bronchial consolidation and small areas of gummatous necrosis. H. and E. $\times 85$.

this case enables one to make a diagnosis of acquired pulmonary syphilis with considerable certainty even in the absence of demonstrable treponemata. The finding of characteristic gummata in various stages of formation and organisation, accompanied by a typical granulation tissue and the absence of tuberculous or pyogenic cellular reaction, confirms the pathological diagnosis.

Case 2.-E. G., 42 years, admitted to Guy's Hospital for cough and shortness of breath on September Igth, I935. Nine months previously she began to expectorate large quantities of sputum. At this time she noticed that she became easily tried, cried readily and did not 


\section{SYPHILIS OF THE LUNG}

wish to go out. She also complained of a sore throat and lost her voice for a few days. During the next month she developed a pain along the left costal margin which was brought on by coughing. A diagnosis of bronchitis and pleurisy was made. A rub was heard in the left axilla. She was admitted to another hospital,

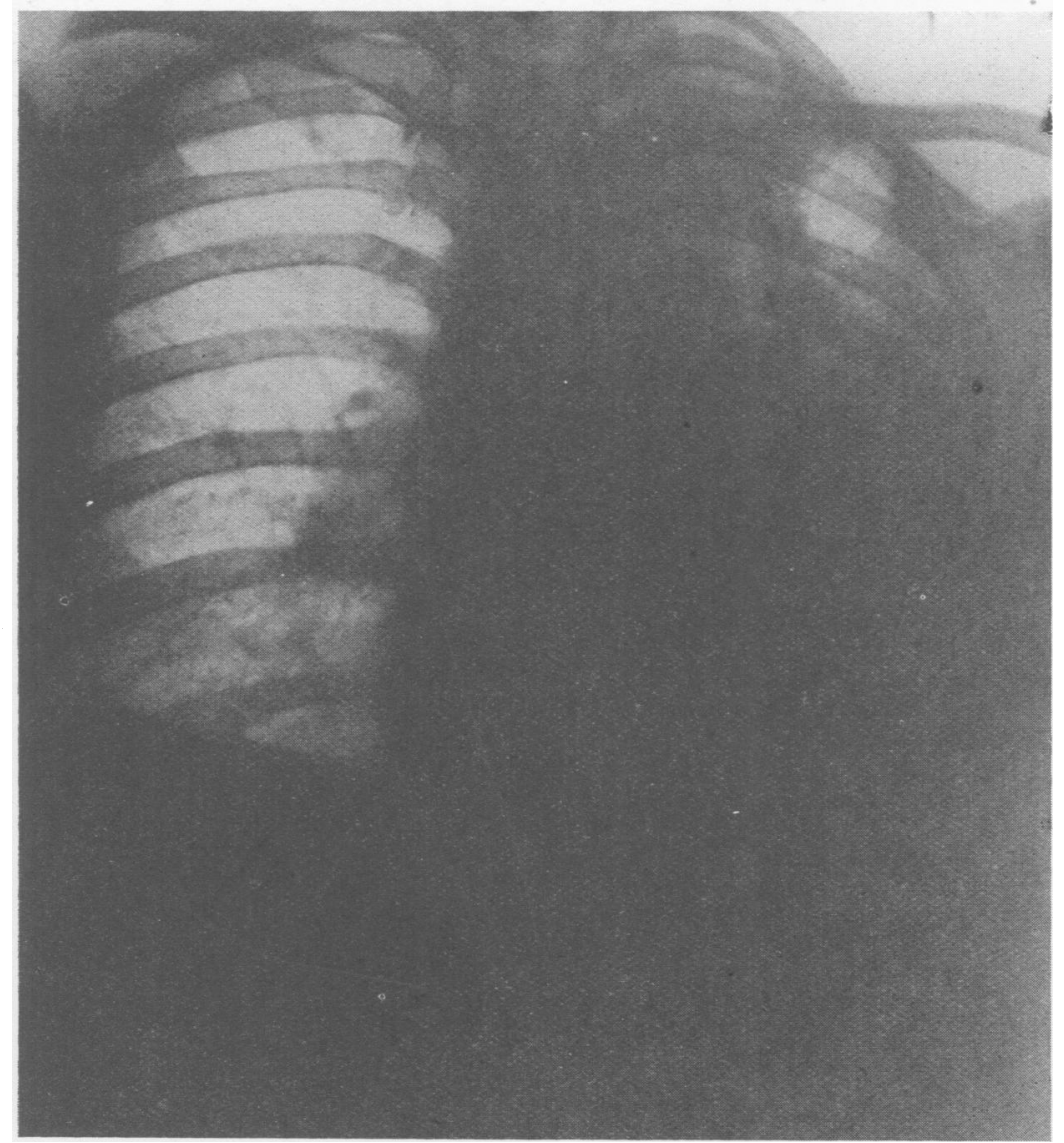

FIG. 9.-Radiograph of the lungs of Case 2, showing a large dense shadow in the left lung.

and while there developed an ulcer of the then hard palate, which was considered to be syphilitic. The Wassermann reaction was positive. On her discharge she attended at Guy's Hospital for anti-syphilitic treatment. She now complained of increasing dyspnœa, and became pyrexial. She was admitted to Guy's Hospital for further investigation. 


\section{BRITISH JOURNAL OF VENEREAL DISEASES}

On admission she was observed to be well nourished, but pale. She had a frequent hacking cough and was bringing up a good deal of purulent sputum. Her temperature was $103^{\circ}$, pulse 130 , and respiration 30 . Her breath was offensive. There was no clinical evidence of any lesion of the heart or aorta.

.The left side of her chest moved very little during respiration and was dull to percussion from apex to base. There was no impairment on the right side. Numerous rhonchi were heard on both sides of the chest, but there was bronchial breathing, with poor air entry, over most of the left side, especially behind. The heart appeared to be slightly displaced to the left. The blood pressure was 124/74. The hæmoglobin was 50 per cent. A large ulcer with punched-out edges was seen in the hard palate. No abnormality was found in the alimentary, nervous or genito-urinary systems.

The sputum examined at this time was muco-purulent and on culture gave a growth of staphylococcus aureus, streptococcus hæmolyticus ( $\alpha$ and $\beta$ types). No tubercle bacilli could be detected, and their absence was confirmed by repeated examinations.

There was some improvement in the general state of the patient with injections of sulphostab, and the intermittent temperature gradually diminished and became normal on September 28th, I935. She continued to bring up 8 to Io oz. of sputum daily, and this was sometimes blood-stained. On October 5th, I935, the temperature rose and continued to swing, reaching $100^{\circ}$ to $104^{\circ}$ at night. In spite of anti-syphilitic treatment, the signs in the chest remained unaltered. The temperature became normal again on October 25th, I935.

In November, bronchoscopy was carried out by $\mathrm{Mr}$. Brock, to whom we are indebted for the following report : "The lower one inch of the trachea and the first part of the left main bronchus were involved in a healing syphilitic process. This had caused considerable narrowing of the lower end of the trachea which had also been rendered flaccid owing to destruction of its rings and therefore flapped on inspiration like a soft-walled tube. The main left bronchus was narrowed to the size of a match-stick and pus was exuding from the stricture. The carina and the adjacent margin of the right main bronchus also showed irregular scarring. The mucous membrane was 


\section{SYPHILIS OF THE LUNG}

healed but the ends of broken cartilaginous rings could be seen shining through it."

The general state of the patient remained about the same ; she continued to bring up several ounces of sputum daily and was subject to bouts of pyrexia lasting two to three days. She was discharged to her home on December 28th, I935, and died there two months later. No postmortem was carried out.

\section{Clinical and Radiological Aspects}

Syphilis may affect the lung in the secondary or tertiary stages. Secondary syphilis can be briefly dismissed. It usually occurs in the form of a bronchitis, due to an extension of the ulcerative process that affects the fauces and pharynx, to the trachea and bronchi. Ornstein (1925) describes a case of this sort in which the patient attended with symptoms of asthma which were relieved by anti-syphilitic treatment. The condition may be localised so that the catarrh is limited to an apex and may give signs suggestive of phthisis (Funk, I9I9). Olsan (I933) believes that a true syphilitic lobar pneumonia may occur in the secondary stage and records a case occurring four weeks after the development of the primary penile sore, spirochæta pallida was demonstrated in the sputum. It is more commonly held, however, that in such cases a true lobar pneumonia is complicating the syphilitic condition. The diagnosis is made by the association of the lung condition with ulceration in the mouth, secondary rash and the effect of antisyphilitic treatment.

A brief survey of the recorded cases of tertiary syphilis of the lung suffices to show that there is no characteristic clinical picture upon which a diagnosis can be made. There is as great variety in its manifestations as in those of pulmonary tuberculosis itself. Most often there is a history of disease of some months or years duration with signs more widespread than the clinical condition of the patient would suggest. At other times, however, the lesion is discovered accidentally in the course of routine screening, in a patient whose main complaint is due to disease of some other organ (Hartung and Friedman, I932, Case 2). The lesion is said most often to affect the middle and lower lobes, but this may well be because 


\section{BRITISH JOURNAL OF VENEREAL DISEASES}

when the apices are left clear it is more likely to be differentiated from tuberculous infection. In spite of statements to the contrary, a number of cases in which the upper lobes have been exclusively affected have been recorded (Raybaud and Jouve, I934, Stoichitza and Cretzu, I935).

The criteria upon which a clinical diagnosis may be made can be briefly summarised as follows :-

(I) An anomalous history of pulmonary disease, often with hæmoptysis, productive cough, loss of weight and fever. The history may be of brief duration or may extend over a period of years.

(2) Exclusion of commoner causes of pulmonary lesions, such as new growth and tuberculosis; the latter by repeated failure to find tubercle bacilli in the sputum.

(3) The presence of a history of syphilitic infection, of associated syphilitic lesions in other organs, and of positive serum reactions such as the Wassermann and Kahn tests.

(4) The effect of anti-syphilitic treatment.

(5) The X-ray appearances, particularly in association with the response to treatment.

In many cases, it is impossible at present to make more than a tentative diagnosis on clinical grounds alone. In our second case the bronchoscopic appearance was mainly responsible for regarding the condition as primarily syphilitic, while in the first case a definite diagnosis of syphilis of the lung was not made clinically. The X-ray appearances vary as widely as do the physical signs and for the same reason, namely, that the underlying pathological changes in the lung differ considerably at different stages of infection, and according to the extent of the lesion. This is well shown by the radiographs in the two cases described.

A survey of the reports of a number of radiologists (Robinson, I935, Watkins, I92I, Golden, I92I) taken in conjunction with the radiological reports in proven cases of pulmonary syphilis, including our own, suggest that the more common $\mathrm{X}$-ray appearances may be grouped as follows :-

(I) Infiltration which may be lobar or patchy in distribution and involving one lobe or part of one of more lobes. There is little or no deviation of the trachea. 


\section{SYPHILIS OF THE LUNG}

(Stoichitza and Cretzu, Raybaud and Jouve, Case I : Denman, I932 and I933, Case 2.)

(2) Opacities roughly oval in shape, most often involving the lower lobes and often without connection to the hilum. These again may be single (Wigley and Saunders, I935, Hartung and Friedman, Case 2), (Lissen, I9I8, Case 3), or multiple (Hartung and Friedman, Case I : Robinson) and may vary in size from a few millimetres to several centimetres in diameter. Rarefied central areas may indicate cavitation. Strands of increased density may radiate from these areas of infiltration into normal lung tissue. (Wile and Marshall, I92I, Case I : Funk, Case 3.)

(3) Generalised accentuation of the bronchial and vascular shadows, often showing a beaded appearance, radiating from the lung roots towards the periphery. (Funk, Case I: Golden, Case 2: Raybaud and Jouve, Case 2.)

(4) One lobe or the whole of one side of the chest may be opaque with deviation of the mediastinum towards the side of the lesion indicating fibrosis or pulmonary collapse. (Golden, Case 2, Jacobs, I935, Cases I and 3: Hartung and Friedman, Case 3.) This may be accompanied by pleural effusion (Lissen, Case 6).

The radiological appearance in many cases is not represented by any one of the groups described above, since when the syphilitic process is present at different stages in the same patient a composite picture may be obtained. The radiograph of Case I (Fig. 2) is of this mixed type, and is referred to again later. Before considering the probable pathological state of the lung corresponding with each of the X-ray appearances described above, the microscopical changes associated with syphilitic infection will be referred to.

It is clear, however, that the diagnosis of pulmonary syphilis can only be made during life after a number of considerations have been taken into account, and commoner conditions excluded. As Stoichitza and Cretzu remark: "La syphilis pulmonaire est une grande simulatrice." Tuberculosis, bronchial carcinoma, pneumokoniosis and mycotic infection may each give physical signs, or radiographs, which, by themselves, are indistinguishable from those of syphilitic infection at some stage. 


\section{BRITISH JOURNAL OF VENEREAL DISEASES}

Consideration of the pathological anatomy of the lesions offers some explanation for the various forms which may be encountered.

\section{Pathological Aspects}

The characteristic features upon which a histological diagnosis of pulmonary syphilis may be made have been summarised by McIntyre (I93I) in his comprehensive review of pulmonary syphilis. Briefly, they are: (I) Syphilis shows less caseation than tuberculosis, (2) Giant cells are rarer in syphilis, (3) Plasma cells are rarer in tuberculosis, (4) Anthracosis is rarer in the scar of syphilis, (5) The adventitia of the blood vessels is more frequently affected in syphilis, (6) There is no endothelioid cell formation in syphilis, (7) The elastic tissue is better preserved in syphilis, (8) Tuberculosis does not show as many subpleural lesions as syphilis, (9) Calcification is rarer in syphilis.

In view of the complete absence of complications either of a mechanical nature such as stenosis of a bronchus, bronchiectasis or cavitation, or of an inflammatory nature such as secondary infection with pyogenic micro-organisms, our first case presented an opportunity to test the validity of such criteria. This was done and confirmed by comparing the lesions with specimens of pulmonary tuberculosis of various types, including one with well-circumscribed tuberculomata.

Furthermore, it was thought that the apparent activity of the lesions and their variety might help to trace the probable course of the syphilitic infection in the lung and its possible sequelæ.

The literature on the pathology of pulmonary syphilis is rendered doubly confusing by (I) attempts to establish a diagnosis on appearances which represent the terminal stages of a syphilitic infection, namely, the character of the residual fibrosis, (2) various classifications of lesions, supposedly syphilitic, without reference to the possible relationship to one another.

Carrera (I920), in a critical study of the lungs in 152 cases of syphilis which came to autopsy, found what he considered characteristic syphilitic pulmonary lesions in twelve. This author considered that a diagnosis of syphilis without the typical inflammatory process cannot 


\section{SYPHILIS OF THE LUNG}

be made. In contrasting his $\mathbf{I}_{52}$ cases of syphilis with 60 cases of pulmonary tuberculosis he was unable to distinguish the fibrosis of syphilis from that of tuberculosis.

In the description of gumma he notes angioblasts and capillaries at the periphery with preservation of the alveolar structure and the elastic tissue of the alveolar walls and of the vessels in the centre. Further, the scars of gummata remained vascular and unpigmented with carbon in contrast with those of tuberculosis. With regard to the peribronchitis, he notes the abundance of plasma cells while the bronchial epithelium is well preserved. In concluding, this author divides his cases into two main groups : (I) five cases of gummata with peribronchial lesions and arteritis, (2) seven cases of fibrosis with arteritis. All twelve showed syphilitic aortitis as well. It is surprising that in this series not a single example of the more acutely pneumonic form was found. The so-called pneumonic form has been described in acquired syphilis by several authors, notably: Rössle (I918), Howard (I924), Letulle and Dalsace (I926), Vivoli (I935), but under this heading are included various types of consolidation, some of which were due to complicating factors, such as secondary infection and bronchiectasis and therefore cannot be considered as a true syphilitic pneumonia. (Stanley), IgII, however, describes "an intense cell proliferation which fills the alveoli and infiltrates the septa, peri-bronchial, subpleural and peri-vascular tissues. It has a peculiar gelatinous appearance and may be called a syphilitic pneumonia." This he considers the most important form of acquired pulmonary syphilis. He describes three other forms : (I) an early diffuse sclerosis, the result of the above, in which the lung is not misshapen and is uniformly tough, (2) gross scarring of the lung with contraction, (3) gummata.

Such an uncomplicated pneumonic form undoubtedly exists and probably represents the earliest lesion in the lung. The diffuse peri-bronchial fibrosis which frequently has a lobar distribution and which is so well recognised can only be the result of an acute inflammatory condition with a similar distribution. Its apparent infrequency at autopsy may well be due to the fact that patients seldom die in this stage. In actuality, the majority of pulmonary 


\section{BRITISH JOURNAL OF VENEREAL DISEASES}

lesions found are either gummata or fibrosis which represent a comparatively late stage of tertiary syphilis.

What may provisionally be termed acute syphilitic pneumonia requires definition and more detailed description than it has hitherto received. Its probable origin and course will be discussed later.

We were fortunate in our case that such a condition was present in the left lung which fits well the description given by Stanley. Anatomically it consisted of a fanshaped area of consolidation which occupied the middle third of the left lung with its apex at the hilum and its base at the pleura. It had well-defined upper and lower margins not unlike the edges of a lobar pneumonia. The mucous membrane of the bronchi and bronchioles appeared normal except for congestion, while the bronchial lumen was uniformly patent and free from exudate. On histological examination the consolidation was due to a fibrino-cellular exudate which filled the alveoli and some of the terminal bronchioles. The cellular portion of the exudate consisted of plasma cells and histiocytes with a varying amount of cytoplasmic granular débris. Uniformly distributed throughout this area were foci measuring a few millimetres in diameter in which the alveoli were necrotic and replaced by a central area of disintegrating cellular material loosely arranged which was surrounded by zones of plasma cells, lymphocytes and macrophages (Fig. 7). In many of these areas strands or rings of swollen columnar bronchiolar epithelium could be seen. These may be considered as foci of necrosis which may proceed to the formation of the socalled " miliary" gummata, of which many were present. The early age of these lesions may be gauged by the general absence of fibroblasts and by the inflammation of the walls of the arteries and veins throughout the affected area. The latter showed severe infiltration of the adventitia and media by plasma cells and lymphocytes which formed well-marked perivascular collars. A moderate number were thrombosed. There was little or no proliferation of capillaries except in the area of gummatous formation. A notable feature was the greater severity and extent of the inflammatory changes in the interstitial tissue, particularly in the alveolar septa and in the blood vessels while the bronchiolar epithelium was relatively undamaged. This strongly suggests that the 


\section{SYPHILIS OF THE LUNG}

condition is primarily an interstitial pneumonia, which may proceed to necrosis of the parenchyma and subsequent formation of a gumma or, in the absence of necrosis, give rise to a diffuse interstitial fibrosis.

The evidence in favour of such a view is demonstrated in the relationship between the acute pneumonia in the left lung and the multiple lesions in the right. The latter showed organisation and repair, which are represented by well-formed gummata and the diffuse fibrosis containing many vessels with endarteritis obliterans. These lesions are considerably older but were distributed over a large area of lung, indicating that the inflammatory reaction of which they are the sequel must have been similarly diffuse. The size and shape of the consolidated areas in both lungs corresponded closely, and since both conditions were typically syphilitic, differing in age rather than character, it is an economy in hypotheses to consider them as two stages in the same process and to assume that the gummata and fibrosis in the right lung are the results of an antecedent pneumonia similar to that in the left. This is further supported by the radiological appearances. The shadow in the right lung preceded that in the left by three weeks. If such a view be accepted the different forms of acquired pulmonary syphilis become related to one another and their pathogenesis is correlated with severity of the infection rather than with differences in the inflammatory reactions of syphilis. There is no essential difference between the so-called miliary gumma and its larger fellow except in size, while the scar of the former will be correspondingly smaller. Both are the result of destruction of parenchyma. Whether the fibrosis is localised or diffuse will depend on the extent of the preceding inflammation and not on differences in character.

The conditions which determine the onset of pulmonary lesions are best considered after their possible origin has been discussed. The earliest changes are confined to the vessels, peri-bronchial and alveolar tissues, indicating that the path of the infection is interstitial rather than bronchial. The respiratory passage may be excluded as a portal of entry inasmuch as involvement of the bronchial epithelium occurs much later, if at all. The survival of the mucosa in an area of necrosis is well illustrated in the accompanying microphotograph (Fig. 8). 


\section{BRITISH JOURNAL OF VENEREAL DISEASES}

The fan-shaped distribution of the lesions is further evidence in favour of an interstitial rather than bronchial spread and again suggests an initial spread from the hilum radiating outwards to the periphery, which accounts for the various sites in which gummata are found. If this is so, infection of the mediastinum probably precedes that in the lung.

Unfortunately, in the published accounts of the autopsy findings in cases of pulmonary syphilis, examination of the cardiovascular system and mediastinum is often incomplete or is not mentioned, so that it is difficult to assess the incidence of associated mediastinal syphilis. In those cases, however, in which the mediastinum has been adequately examined and which are available in the literature, syphilitic aortitis or aneurysm of the thoracic aorta has been present.

Carrera's series of I2 cases all showed syphilis of the heart and aorta. Robertson and Robertson (1932) reported 2 cases of pulmonary syphilis and both showed syphilitic aortitis. Aortitis was present in one and aneurysm in the other of the two cases reported by Denman (I933). Vivoli (I935), who reviews the clinical and pathological forms of acquired pulmonary syphilis in a series of papers based on 25 cases, notes the presence of aortitis and/or aneurysm in 75 per cent. Analysis of his cases, however, considerably increases the incidence : I8 out of 25 cases came to autopsy; and of these, I4 in which the pathological criteria of pulmonary syphilis were satisfied, all showed syphilitic aortitis. Of the remaining 4 which the author accepts as cases of pulmonary syphilis, but which, in view of the complicating factors, should be excluded, I showed rupture of an aneurysm into a bronchus on the same side as the pulmonary lesions, I showed an aneurysm adherent to and partially occluding the bronchus of the same side, I showed an aneurysm of the pulmonary artery, and the last gangrene of the lung and pyæmia.

Two cases of gummata of the lung verified at autopsy performed at this hospital both showed aortitis. The association in these reported cases is much too high to be the result of fortuitous coincidence even allowing for the high incidence of aortitis in syphilis. Symmers (I9I6) found 3I4 cases of acquired syphilis in 4,880 autopsies, or a total incidence of 6.5 per cent. Aortitis was found I 75 times, or in $55^{\circ} 7$ per cent. Syphilitic changes in the 


\section{SYPHILIS OF THE LUNG}

respiratory tract were encountered thirty-five times, or in I0.5 per cent. Of these 35 cases, the larynx was affected in 12 , the trachea in 4 , the nasal septum in 4, the hard palate in I, while I 2 cases were called chronic interstitial pneumonia, and therefore represented 3.8 per cent. of all cases of syphilis.

The statistical evidence lends strong support to the view that aortitis is invariably present in syphilitic infection of the lung parenchyma, while the anatomical evidence strongly suggests that the lesions in the lung are preceded by and are the result of extension of the infection from the mediastinum.

If this is accepted, another factor is added to the list of clinical and pathological criteria in the diagnosis of pulmonary syphilis.

\section{Discussion}

It remains to attempt to correlate the clinical and radiological findings with the probable underlying condition in the lung, in view of the evidence obtained from the two cases reported in this paper. Tertiary syphilis may affect the lung in two ways, either by invasion of the pulmonary interstitial tissue from the hilum, as in Case I, or as a result of syphilitic lesions of the trachea or bronchi, as in Case 2 ; in the latter group may be included those cases in which bronchial constriction with subsequent bronchiectasis occurs as the result of pressure from an aneurysm of the aorta.

This second group needs little consideration and will be discussed first. The signs and symptoms are those which accompany bronchiectasis or fibrosis of whatever origin and are secondary to bronchial obstruction by a gummatous process. It is only possible to diagnose the condition with certainty by actual observation of the bronchi during life, as in our second case, or possibly at post-mortem. The lungs themselves will show no specific evidence of syphilis, and therefore a diagnosis is in many cases impossible. It is unlikely that pulmonary symptoms will be produced till healing of the gumma with fibrosis has begun. For this reason, treatment is not likely to be successful, since it is attempting to deal with end results rather than with active disease. The radiological appearances correspond with those described in the fourth group. 


\section{BRITISH JOURNAL OF VENEREAL DISEASES}

The clinical findings are far more variable in those cases in which syphilitic infiltration of the lung itself occurs.

The pneumonic phase may give signs of consolidation limited to one lobe or part of one or more lobes. The radiological appearances vary similarly from complete consolidation of one lobe with little or no displacement of the trachea or may show infiltration spreading from the root with tongue-like projections into presumably normal lung and involving parts of two or more lobes. The latter appearance is shown on the right side in Case $I$ in the earlier Fig. I, while consolidation is present in the left lung in Fig. 2, taken three weeks later. Complete resolution, as shown by subsequent radiographs, commonly follows adequate anti-syphilitic treatment in these cases. Should necrosis develop, the formation of a gumma or gummata may occur and will be responsible for the changes we have described in the second group of radiological appearances, which will vary according to the number and size of the gummata. Cavitation may occur as a result of the discharge of a gumma into a bronchus and will show accordingly.

Organisation of the gummatous or pneumonic processes. leads to fibrosis, probably giving rise to the increased pulmonary markings described in the third group. The beaded appearance referred to is thought to indicate the presence of miliary gummata. The simultaneous occurrence of gummata and diffuse fibrosis is seen to have occurred in the right lung of our first case. The radiograph of this lung, however, shows no evidence of the gummata which were subsequently found, but the evident contraction of the area of infiltration (Fig. 2), shown by displacement of the trachea towards that side, was subsequently confirmed by anatomical findings as being due to fibrosis. Where the scarring is localised and severe, the condition known as pulmo lobatum develops and can sometimes be recognised radiologically (Prevot, I935). When fibrosis has occurred, anti-syphilitic treatment can never restore the normal radiological appearance of the lung.

Finally, it is possible that extensive fibrosis may develop as a terminal stage, giving an appearance radiologically indistinguishable from that produced by bronchial constriction due to gummatous involvement of a main 


\section{SYPHILIS OF THE LUNG}

bronchus. The appearance would coincide with that described in the fourth group. Treatment in such cases is always ineffective.

\section{CONCLUSIONS}

(I) Acute syphilitic pneumonia undoubtedly exists and probably represents the earliest lesion in pulmonary syphilis.

(2) Syphilitic pneumonia is primarily interstitial and may lead to (a) gummata; (b) chronic interstitial fibrosis.

(3) It is suggested that pulmonary syphilis is always associated with and secondary to syphilitic aortitis and is more frequent than has hitherto been believed.

\section{SUMMARY}

(I) Two cases of pulmonary syphilis are described, one of which showed a syphilitic pneumonia at autopsy.

(2) The pathogenesis and incidence of pulmonary syphilis are discussed.

\section{REFERENCES}

Carrera, J. L. (I920) : Am. J. Syph., 4, I.

Denman, H. C. (I932) : Ann. Int. Med., 5, 895 ; (I933), N. Y. S. J. Med., 33, I438.

Funk, E. H. (1919-20), Amer. Rev. Tuberc., 3, 754 ; (1923), Med.

Golden, R. (I92I) : Amer. J. Roentgen., 8, 502. Clin. N. Amer.

Hartung, A., and Friedman, I. (I932): J. Amer. med. Ass., 98,

HowARD, C. P. (I924): Am. J. Syph., 8, r. I969.

JACOBS, M. (I935): Amer. Rev. Tuberc., 31, 453.

Letulle, M., and Dalsace, J. (I926) : Pr. méd., 34, 385.

Lissen, H. (I9I8) : Amer. J. med. Sci., 155, 356.

McIntyre, M. C. (I93I) : Arch. Path., 11, 258.

Olsan, H. T., and ChAmbers, S. O. (I933) : Calif. and Western Med.,

Ornstein, G. G. (I925) : Med. Clin. N. Amer., p. 357.

39, 185 .

Prevot, R. (I935): Roentgen. Praxis, 7, 686.

Raybaud, A., and Jouve, A. (I934) : Arch. méd. Chir. Appar. resp., $9,337$.

Robertson, W. E., and Robertson, H. F. (I932) : Int. Clin., 3, 23 RoBinson, W. W. (I935): Radiology, 25, 596.

Rössle, R. (I9I8) : Münch. med. Wschr., 36, 992.

Stanley, J. D. (IgII) : Brit. Med. J., 2, 802.

Stoichitza, N. N., and Cretzu, V. (I935): Arch. méd. chir. Appar. 


\section{BRITISH JOURNAL OF VENEREAL DISEASES}

Symmers, D. (rgi6) : J. Amer. med. Ass., 66, II57.

Vivoli, D. (1935): Prensa. méd. argent, 22, ii, I569, I627, I736,

Watkins, W. W. (I92I) : Amer. J. Roentgen., 8, 259.

Wile, V. J., and Marshall, C. H. (I92I): Arch. Derm. Syph., N. Y., 4, 37 .

Wigley, P. E., and Saunders, R. B. (r935) : Radiology, 25. 